\title{
Settlement Analysis of Saturated Tailings Dam Treated by CFG Pile Composite Foundation
}

\author{
Jinxing Lai, ${ }^{1,2}$ Houquan Liu, ${ }^{2}$ Junling Qiu, ${ }^{2}$ and Jianxun Chen ${ }^{1}$ \\ ${ }^{1}$ Shaanxi Provincial Major Laboratory for Highway Bridge \& Tunnel, Chang'an University, Xian 710064, China \\ ${ }^{2}$ School of Highway, Chang'an University, Xi'an 710064, China \\ Correspondence should be addressed to Jinxing Lai; 373159626@qq.com and Jianxun Chen; chenjx1969@163.com
}

Received 23 September 2015; Revised 20 December 2015; Accepted 13 January 2016

Academic Editor: Stefano Sorace

Copyright (c) 2016 Jinxing Lai et al. This is an open access article distributed under the Creative Commons Attribution License, which permits unrestricted use, distribution, and reproduction in any medium, provided the original work is properly cited.

\begin{abstract}
Cement fly ash gravel (CFG) pile composite foundation is an effective and economic foundation treatment approach, which is significant to building foundation, subgrade construction, and so forth. The present paper aims at investigating the settlement behaviors of saturated tailings dam soft ground under CFG pile composite foundation treatment, in which FEM and laboratory model test were utilized. The proposed findings demonstrate that CFG pile treatment is effective in reinforcing saturated tailings dam and loading has little influence on settlement of soil between piles. The variation of soil between piles settlement in FEM has a good agreement with the laboratory model test. Additionally, the cushion deformation modulus has a small effect on the composite foundation settlement, although the cushion thickness will generate certain influence on the settlement distribution of the composite foundation.
\end{abstract}

\section{Introduction}

With the rapid development of highway construction in China, soft ground treatment, as a limiting factor for construction schedule, costs, and engineering quality, has received more and more attentions. CFG pile composite foundation was extensively used in ground treatment due to its large extent in bearing capacity improvement, being applicable to various ground cases, rapid construction, low engineering costs, and so forth [1-5]. CFG pile is high bond strength pile formed by cement, fly ash, gravel, aggregate chips, sand, and a moderate amount of water, together with soil between piles and cushion to form composite foundation. In the 1960s, engineers applied gravel pile to consolidate natural soft ground, and thereafter it was regarded as composite foundation. Foundation Institute of China Academy of Building Research developed CFG pile composite foundation in the early 1990s [6], which greatly facilitated the development of composite foundation theory and design method. During the highway construction, CFG pile composite foundation was commonly used under flexible foundation of embankment load, in which CFG pile composite foundation was confronted with larger settlement, lack of developing of bearing capacity of pile, and unstable foundation [7-12].

To date, an increasing number of analytical, experimental, and numerical approaches have been developed to investigate the behaviors of CFG pile composite foundation under flexible foundation. In terms of theoretical analysis, for example, He et al. [13] explored the function mechanism of cushion in the CFG pile composite foundation and proposed an analytic formula of optimum pile spacing and actual replacement rate. Ji et al. [14] conducted research on load transfer mechanism of the CFG pile composite foundation on soft ground of expressways. Many researchers have carried out experimental studies to investigate the performance of CFG composite foundation. For instance, Huang [15] implemented study on the related function of CFG composite foundation under thick cushion via static load test. Zhang et al. [16] performed detailed analysis on pile-soil stress ratio with different pile spacing under embankment load through field test. Zhang et al. [17] discussed the impact of pile spacing on subgrade stability under embankment load by centrifugal model test. Numerical investigation has also been applied to study the CFG composite foundation. For example, Zheng et al. [18] 


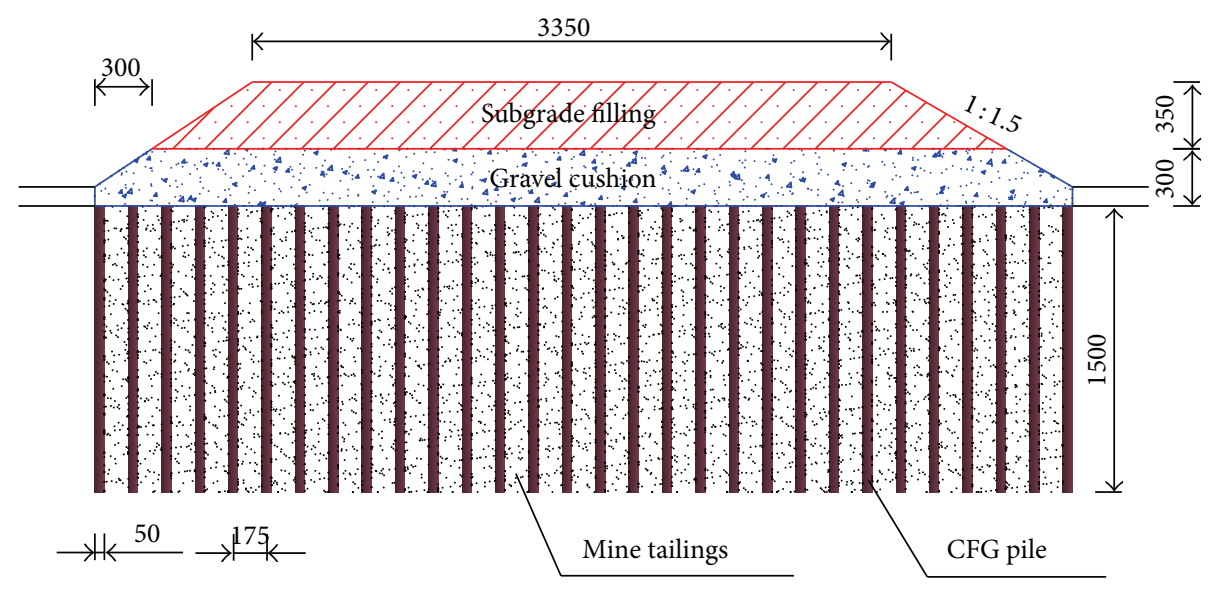

(a) Cross section diagram (unit: $\mathrm{cm}$ )

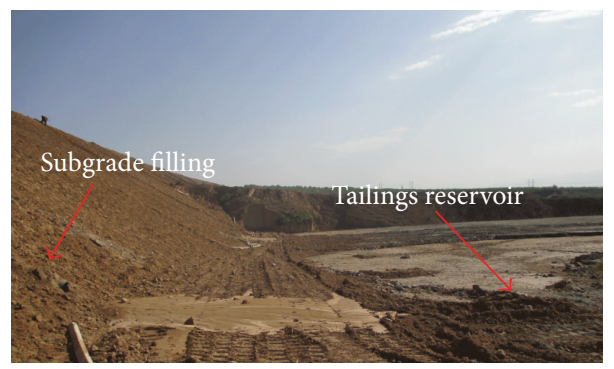

(b) In situ diagram

FIGURE 1: Cross section and in situ diagram of CFG pile composite foundation.

used ANSYS software to investigate the behaviors of composite CFG-lime pile foundations under various load distributions. Wang et al. [19] studied the determination approach of bearing capacity of CFG pile composite foundation under the railway flexible foundation based on FEM. Zhan and Jiang [20] reported the liquefaction resistance of the CFG pile composite foundation on high-speed rail subgrade via FEM. However, studies on using CFG pile composite foundation to reinforce special soft ground of saturated tailings dam are deficient. Tailing dam is a dangerous source of artificial debris flow with high potential energy $[21,22]$. Serious accidents of dam breaking should be avoided. Thus, it is of great necessity to explore the performance characteristics of saturated tailing dam used as high-level highway subgrade. Hence, the present paper employed FEM and compared the results of laboratory model test to implement detailed analysis on the settlement characteristics of the CFG pile composite foundation in saturated tailing dam under embankment load, which can provide experience to the design and construction of the CFG pile composite foundation in soft ground.

\section{Engineering Overview}

Wangzhuangbao-Fanshi expressway is located in Shanxi, China; the route has nine sections drilling through or passing near saturated tailing dam area. Because the bearing capacity could not meet design requirements in the nine sections, three treatments (cushion, cement soil plus cushion, and
CFG pile composite foundation) were employed in different sections, and the CFG pile composite foundation was applied at the sites between $\mathrm{K} 55+650$ and $\mathrm{K} 55+770$ sections of Yuehong Magnetic Plant saturated tailings dam (the bottom of tailing dam is " $\mathrm{V}$ " shaped gully, and the bottom layer is loess layer), which showed the best reinforcement effect among the three treatments. The expressway passed through the middle of tailings reservoir in the form of filling subgrade, in which CFG pile composite foundation was used to reinforce saturated tailings sand foundation (Figure 1). The length of CFG pile is $15 \mathrm{~m}$ and the pile diameter is $0.5 \mathrm{~m}$ with the pile spacing of $1.75 \mathrm{~m} .3 \mathrm{~m}$ gravel cushion was filled at the bottom of the subgrade after drainage.

\section{Finite Element Analysis of CFG Pile Composite Foundation}

3.1. Finite Element Model and Selected Parameters. The dimensions of the FE model are of $14 \mathrm{~m} \times 10 \mathrm{~m} \times 31.5 \mathrm{~m}$. Displacements are restricted at the model boundaries in the normal direction to their respective planes. From the bottom to the top of the FE model, the soil profiles consist of loess layer, saturated tailings sand layer, gravel cushion, and subgrade filling layer, respectively, in which the depths of saturated tailings sand and loess layers are $25 \mathrm{~m}$ in total, gravel cushion is $3 \mathrm{~m}$, and subgrade filling is $3.5 \mathrm{~m}$. The interface of all soil layers was simplified to be plane, and soil was assumed to be solid element which obeys elastic perfectly plastic 


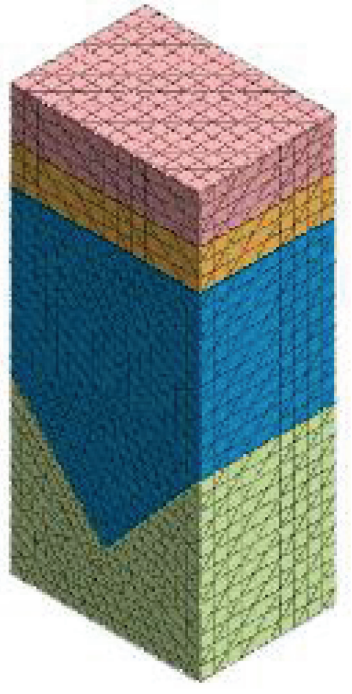

(a) Integral model

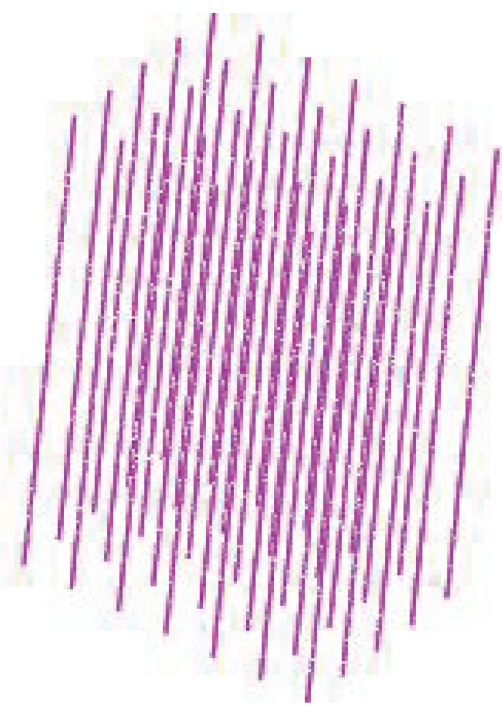

(b) Pile-soil contact element

FIgURE 2: FE model of composite foundation and pile-soil contact element.

TABLE 1: Physical parameters of soils and CFG piles [24].

\begin{tabular}{|c|c|c|c|c|c|c|}
\hline Number & Material types & Modulus/MPa & Poisson's ratio & $\begin{array}{c}\text { Soil unit } \\
\text { weight } /\left(\mathrm{kN} / \mathrm{m}^{3}\right)\end{array}$ & Cohesion $/ \mathrm{kPa}$ & $\begin{array}{l}\text { Angle of internal } \\
\text { friction } /\left(^{\circ}\right)\end{array}$ \\
\hline 1 & CFG pile & 1600 & 0.25 & 21.5 & 900 & 35 \\
\hline 2 & Saturated tailings sand & 2 & 0.32 & 18.7 & 7 & 40 \\
\hline 3 & Loess & 40 & 0.25 & 20 & 35 & 45 \\
\hline 4 & Gravel cushion & 140 & 0.16 & 20 & 0 & 36 \\
\hline 5 & Filling layer & 100 & 0.2 & 19 & 15 & 20 \\
\hline
\end{tabular}

Mohr-Coulomb yield criterion [23]. Besides, the length of CFG pile is $15 \mathrm{~m}$, pile diameter is $0.5 \mathrm{~m}$, and pile spacing is $1.75 \mathrm{~m}$. Beam element was employed for simulation. CFG pile was simplified as linear elasticity model, and 35 CFG piles in total were simulated. Contact element was constructed between pile and soil. Uniform load was added to composite foundation, and three loadings were added during the entire simulation process. The loads used in the simulation were $50 \mathrm{kN} / \mathrm{m}^{2}, 100 \mathrm{kN} / \mathrm{m}^{2}$, and $150 \mathrm{kN} / \mathrm{m}^{2}$, respectively, based on the in situ loading conditions. The overall model of composite foundation is shown in Figure 2, and geotechnical properties of CFG pile and soil layers are summarized in Table 1. Soil layers parameters were acquired from the field test [24], and the CFG piles parameters were typical values [15]. Modulus of deformation was used for soil, and modulus of elasticity was employed for the CFG piles.

\subsection{FEM Analytical Results}

(1) Settlement Variation with Depth. Figure 3 shows the FEM results of the whole settlement distribution of CFG pile composite foundation with depth. Figure 4 demonstrates the variation of soil layers settlement with depth. To investigate the settlement distribution of different soil layers, the central pile position of CFG pile composite foundation was selected for analysis. From the surface to the bottom of the model, totally 64 points $(0.5 \mathrm{~m}$ interval) were chosen for settlement analysis. Figure 4 clearly shows that similar settlement trend is found among different loadings, settlement is consistent and stable in each soil layer, and obvious variation commonly occurs to the interface of different layers. Overall, the settlement of composite foundation almost decreases with the increase of depth. However, at a depth of $3.5 \mathrm{~m}$, the interface of the filling layer and gravel cushion, settlement exhibits a significant increase, and gravel cushion has the maximum settlement among the soil layers which reaches $22.4 \mathrm{~cm}$ when the load is $150 \mathrm{kPa}$. Hence, it seems extremely important to improve cushion material performance in the reinforcement of soft soil foundation. In the area of soil between piles (6.5-21 $\mathrm{m}$ depth), the settlement basically presents very small changes, which demonstrates that the saturated tailing dam has good settlement performance after reinforcement by CFG pile composite foundation. The settlement is extraordinarily small when the depth reaches $25 \mathrm{~m}$ and then it slowly decreases to zero with further increase of depth, which is due to the stable loess layer and reasonable pile length of $15 \mathrm{~m}$ in the soil layers.

(2) Settlement Variation with Horizontal Distance. The present analysis aims at exploring horizontal variation of different soil 


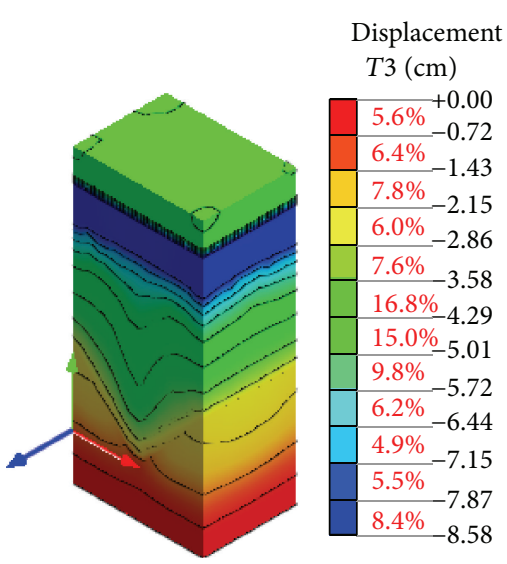

(a) Case of subgrade filling construction procedure

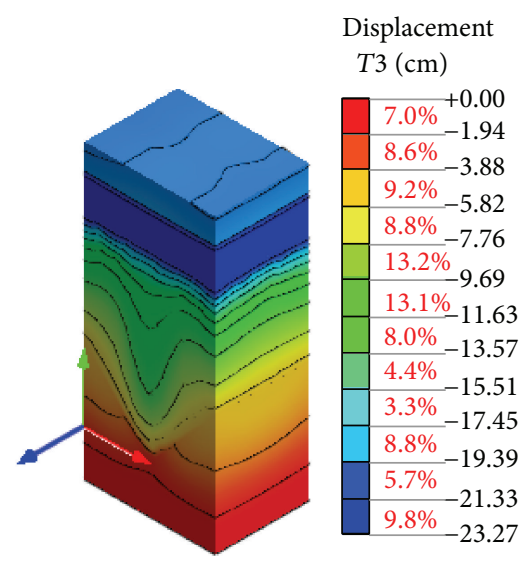

(b) Case of loading of $150 \mathrm{kPa}$

FIGURE 3: Distribution of soil settlement in different soil layers.

Depth $(\mathrm{m})$

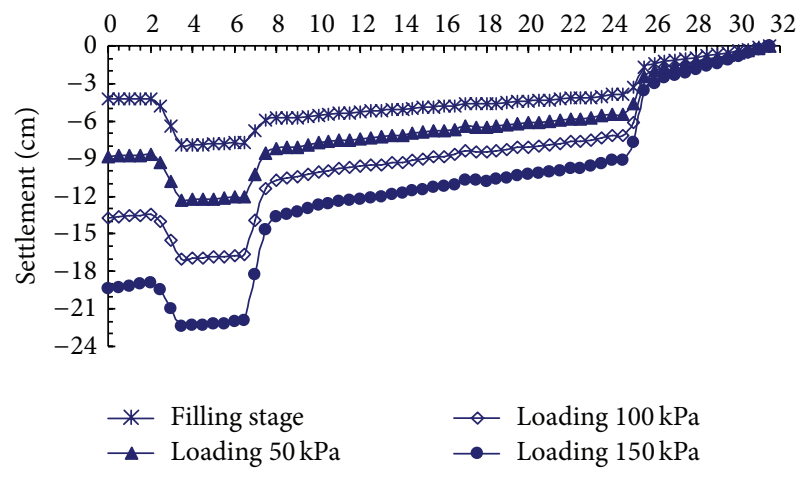

FIGURE 4: Variation of soils settlement with depths.

layers settlement. Positions were selected by $0.5 \mathrm{~m}$ interval horizontally. For each analysis position, from the surface to the bottom of the model, settlement of the center of filling layer, center of cushion, surface of soil between piles, center of soil between piles, bottom of soil between piles, and center of loess layer were selected for analysis. The results indicate that settlement is horizontally stable, as depicted in Figures 5 and 6. Settlement in the filling layer and cushion are much stable over horizontal distance. Settlement fluctuation is detected in the top surface of soil between piles, with amplitude of about $3.5 \mathrm{~cm}$, which points out that the pile top has penetrated into cushion and resulted in differential settlement on surface of the pile top. Zhao et al. [25] conducted the study on the settlement computed by considering the effect of CFG pile top penetrating into cushion and proposed the computed method of CFG pile composite foundation settlement with the integration of composite pile-soil-cushion. Additionally, obvious "V" shaped central (central pile) settlement shift is found in the center and bottom of the soil between piles, and radius of settlement shift is about $3 \mathrm{~m}$, which is consistent with the FEM CFG composite foundation settlement reported in $[26,27]$. In summary, the settlement is consistent and stable

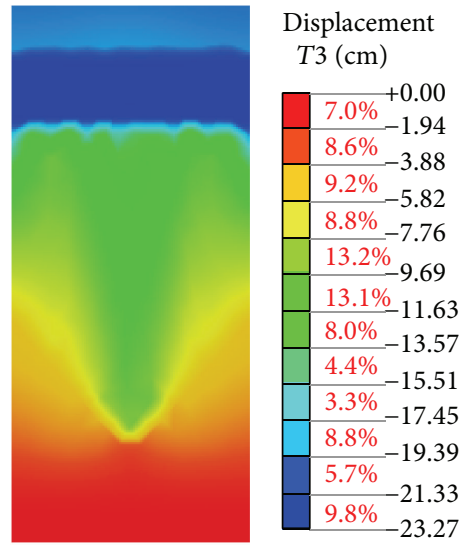

FIGURE 5: Variation of soil settlement in horizontal direction.

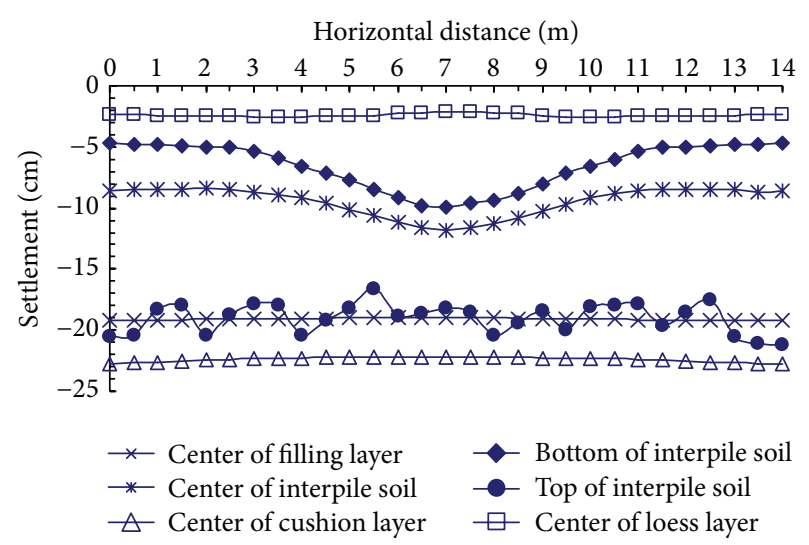

FIGURE 6: Variation of soil settlement with subgrade transverse distance.

relatively at subgrade transverse, which reveals that there is a favorable effect of CFG composite foundation treatment.

(3) Settlement Variation with Load. This section aims to investigate the variation of settlement with load. Points in 


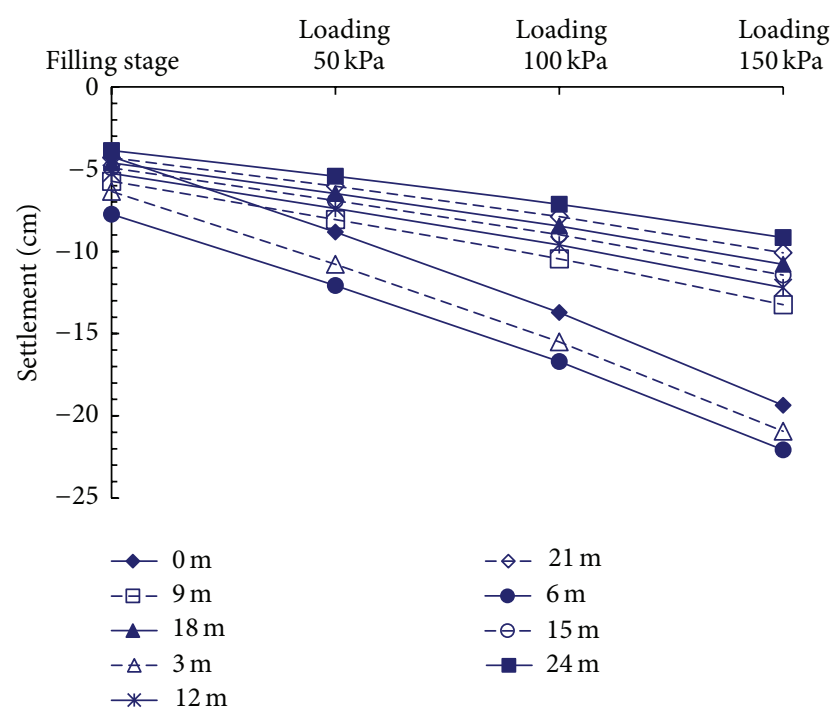

Figure 7: Variation of soils settlement under different loads.

the central pile position ( $3 \mathrm{~m}$ interval) were selected to study settlement under load of filling construction and three different loadings. The variation of settlement for different soil layers with the load is illustrated in Figure 7. A greater increasing range of the settlement in the depth range of 0 $6 \mathrm{~m}$ is observed, in which the increasing range at $0 \mathrm{~m}$ is the greatest, from $4.2 \mathrm{~cm}$ to $19.3 \mathrm{~cm}$. This declares that it has a significant effect on the subgrade surface after loading. In the saturated tailing sand area with CFG pile treatment, the settlement increases with the increase of load with a small increasing range which is stable around $2.1 \mathrm{~cm}$.

(4) Settlement Variation with Time. The settlement in the first 15 days was analyzed by using the settlement-consolidation model. Loading was added every five days, and a total of three loadings were simulated. Settlement value was recorded each day. Settlement of the soil between piles at the central pile position (the maximum settlement) was selected for analysis. Settlement which occurred during construction phase was not taken into consideration, and only settlement happening in loading process was studied. The variation of settlement with time in composite foundation is presented in Figure 8 (where "1-2" means the settlement which was recorded at the second day after the first loading), which indicates that the settlement rate of various soil layers decreases with time. The settlement of various soil layers gradually becomes stable. In addition, after the third loading, the settlement rate of soil between piles below the depth of $9 \mathrm{~m}$ from $1.1 \mathrm{~cm}$ in the first loading reduces to $0.2 \mathrm{~cm}$, and that of filling layer and gravel cushion reduces from $2 \mathrm{~cm}$ to $0.4 \mathrm{~cm}$. The computed settlement of soil between piles is observed to diminish at a rapid rate with time. It indicates that the saturated tailings dam presents better settlement stability after CFG pile treatment and further proves that CFG pile composite foundation obtains a favorable effect.

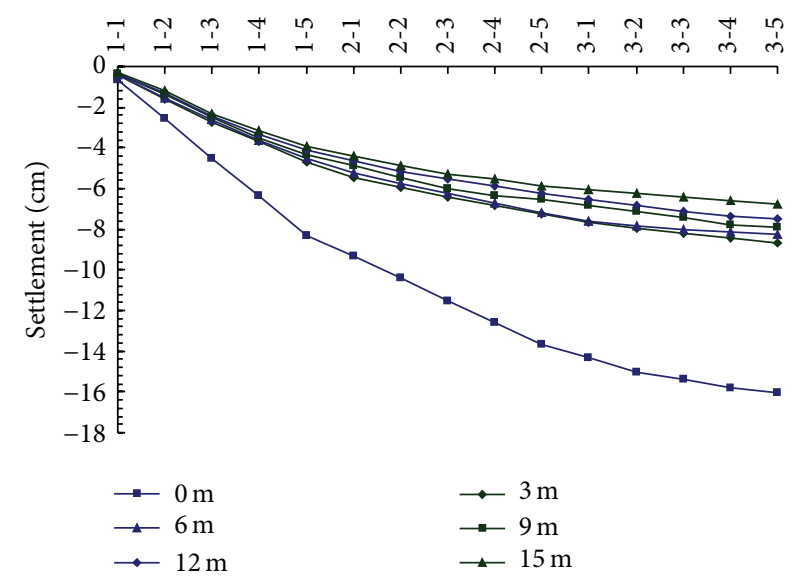

FIgURE 8: Variation of soil settlement with time.

\section{Laboratory Model Test}

4.1. Test Scheme. Xing [24] had conducted laboratory model test on the CFG pile composite foundation, which was based on the saturated tailings dam of Yuehong Magnetic Plant at $\mathrm{K} 55+650-\mathrm{K} 55+770$ sections of Wangzhuangbao-Fanshi expressway in Shanxi, China. The geometric similarity ratio $\alpha_{l}$ of the model test is 10 , and the dimension for model groove is $2 \mathrm{~m} \times 2 \mathrm{~m} \times 2 \mathrm{~m}$. The model trough is shown in Figure 9 .

The CFG model pile was made of stone chip, sand, gravel, fly ash, cement, and water. The length of the CFG pile is $1.5 \mathrm{~m}$, diameter is $0.05 \mathrm{~m}$, and $35 \mathrm{CFG}$ piles in total were employed in the model test. Layout plan of CFG pile in the model test is shown in Figure 10. The in situ picture of the model test is shown in Figure 11.

4.2. Comparison of Laboratory Model Test with FEM. The results of the FEM and laboratory model test on the CFG pile composite foundation settlement demonstrate that the settlement of various soil layers is consistent and stable at different pile positions. Therefore, the soil between piles at central pile (with maximum settlement) was selected to carry out the comparative analysis on the results between the FEM and laboratory model test which investigated the variation of composite foundation settlement with load, depth, and time. And settlement value of the laboratory model test results was multiplied by settlement similarity ratio $\alpha_{l}=10$ according to the similarity theory.

Settlement variation of soil between piles with load is illustrated in Figure 12. The results indicate that settlement of CFG pile composite foundation under load changes evenly and finally becomes stable. The settlement increasing range in the FEM is larger than that from the laboratory model test. Obvious variation between the laboratory test and FEM modeling happens to surface of the soil between piles, which is small below the surface area. This is because FEM takes cushion and subgrade filing into account; settlement increasing range of soil between piles on the pile top surface is larger than other depths obviously.

Figure 13 shows the variation of settlement of soil between piles with depth. The laboratory model test results indicate 


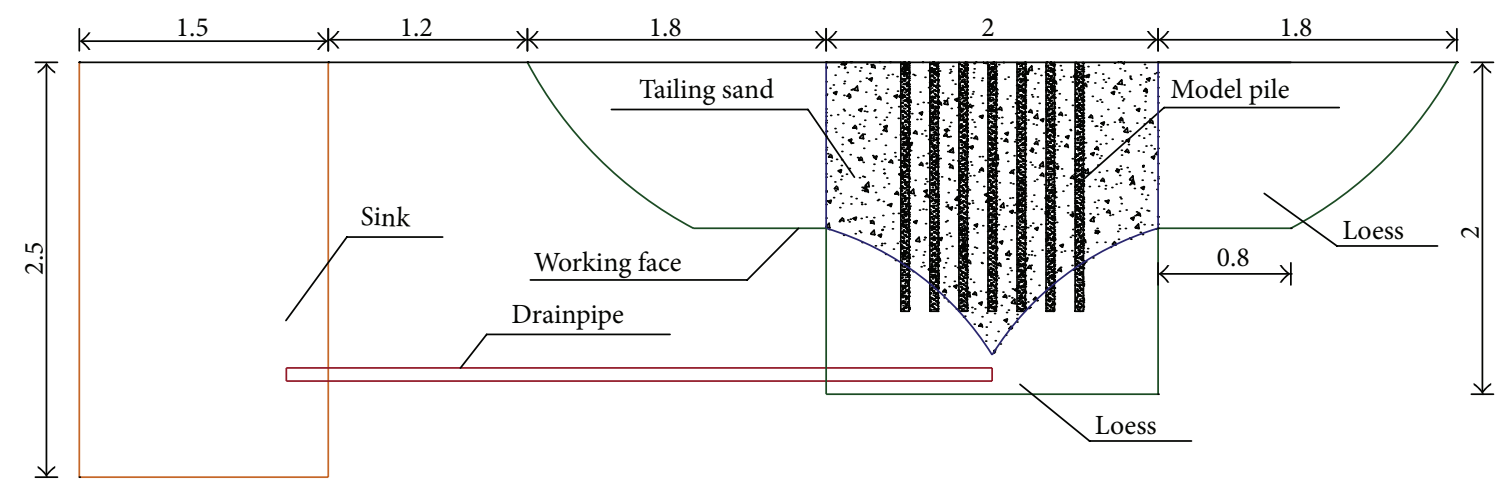

FIGURE 9: Laboratory model test of CFG pile (unit: $\mathrm{m}$ ).

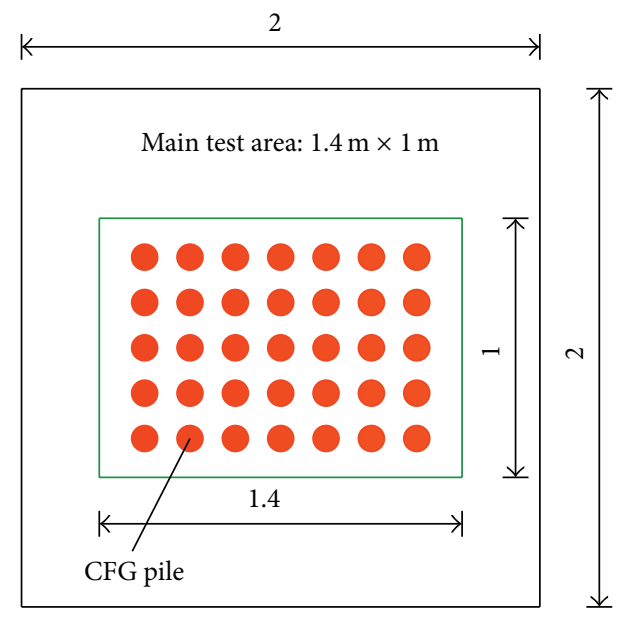

FIGURE 10: Layout diagram of CFG piles (unit: $\mathrm{m}$ ).

that the settlement decreasing range is relatively stable with the depth. Based on the FEM results, the settlement decreasing range is relatively large at the intermediate depths of $0-$ $5 \mathrm{~m}$, while it becomes small and tends to be stable below the depth of $5 \mathrm{~m}$. Both the experimental results and FEM results show that the settlement of saturated tailing dam after CFG pile treatment exhibits even and stable changes with depth.

Presented in Figure 14 is the variation of settlement of soil between piles with time. The results of FEM show a good agreement with the laboratory model test. The settlement rate at different depths becomes stable in the later period. This indicates that the settlement of CFG pile composite foundation becomes stable gradually and CFG pile composite foundation has distinctive settlement characteristics and reinforcement effects.

The variation of settlement of soil between piles in FEM exerts a good agreement with the laboratory model test; thus, to a certain extent, the FEM results can better reflect the settlement changes in practical engineering. The results from FEM analysis show that the cushion has the maximum settlement, and the average value of settlement difference between cushion and soil between piles reaches about $7 \mathrm{~cm}$. Hence, it is quite important to improve cushion performance to reduce the settlement of composite foundation. And there have been some studies which discussed and introduced the effects of the cushion on the properties of composite foundation [28-30]. Both FEM and laboratory model test signify that the settlement of soil between piles tends to be consistent and stable; thus, CFG pile composite foundation has obvious treatment effect.

\section{Influence of Cushion Parameters on the Settlement of CFG Pile Composite Foundation}

Pile-cushion system is important for the success of CFG pile composite foundation [15]. According to the FEM results, cushion possesses the largest settlement compared to other soil layers. Hence, it is essential to understand the influence of the cushion thickness and modulus on the CFG pile composite foundation.

5.1. The Influence of the Cushion Modulus on Settlement of the CFG Pile Composite Foundation. The deformation modulus of cushion in the aforementioned model is $E_{0}$ $=140 \mathrm{MPa}$. The present section aims at investigating the influence of the cushion deformation modulus on the composite foundation settlement. Settlement of the central pile position was analyzed using different values of deformation modulus of cushion $(50,100,150,200,250$, and $300 \mathrm{MPa})$. The settlement results from FEM analysis with $E_{0}=50$ and $300 \mathrm{MPa}$ are shown in Figure 15. Composite foundation settlement at different depth under the deformation modulus of 50,150 , and $250 \mathrm{MPa}$ is presented in Figure 16. Figure 17 shows the variation of the settlement with the modulus at the depths of 0,3 , and $6 \mathrm{~m}$. With the increase of cushion deformation modulus, the settlement decreases at $0-5 \mathrm{~m}$, but settlement increases slightly below depth of $5 \mathrm{~m}$. When the deformation modulus is relatively small, increasing the deformation modulus will create a certain effect on the subgrade filling and cushion; specifically, the settlement of the two layers can be reduced by $0.8 \mathrm{~cm}$ when the deformation modulus increases from $50 \mathrm{MPa}$ to $100 \mathrm{MPa}$. The effects on settlement become very small when the modulus is greater than $100 \mathrm{MPa}$. Additionally, improving modulus has little influence on the settlement of the saturated tailings 


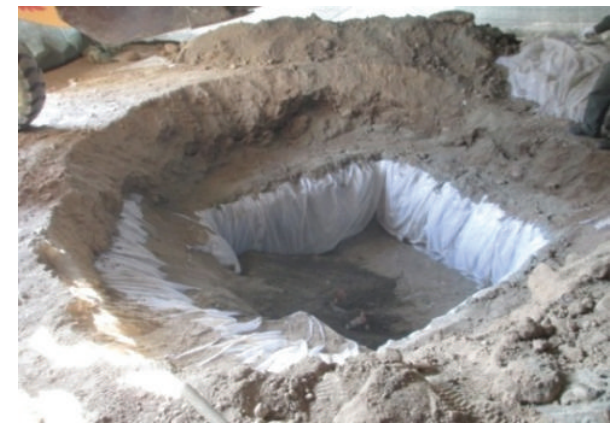

(a) Model trough

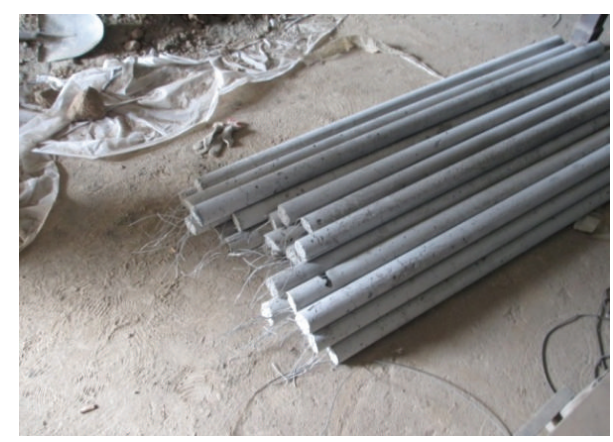

(b) CFG model pile

FIGURE 11: Laboratory model test model [24].

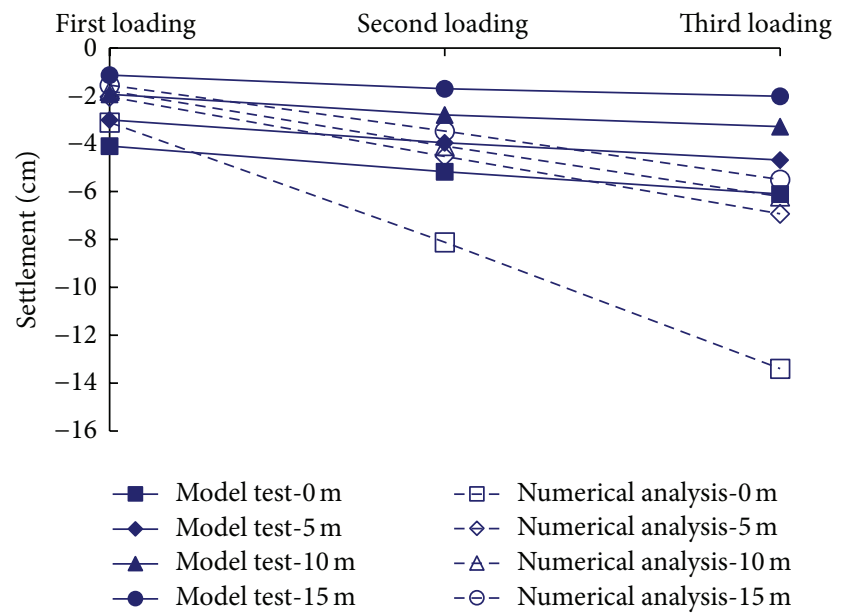

FIGURE 12: Comparison of interpile soil settlements under different loads between FEM and model test.

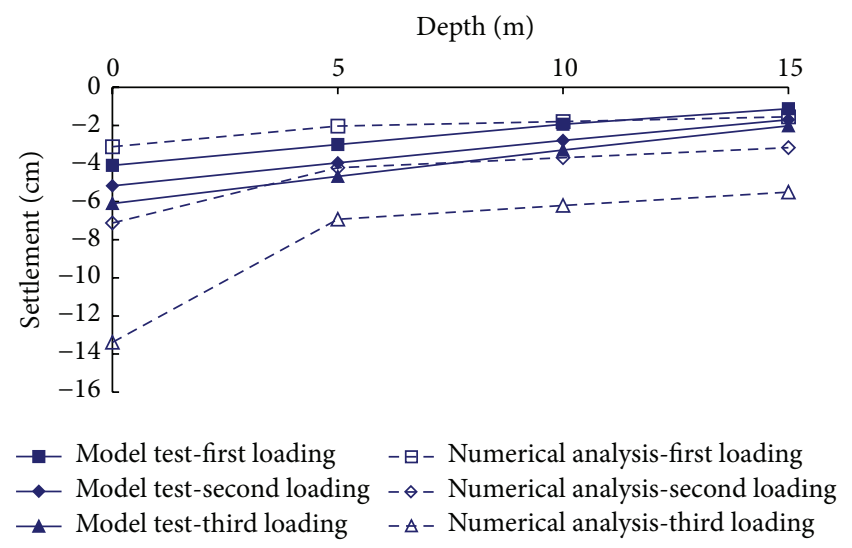

FIGURE 13: Comparison of interpile soil settlements at different depths between FEM and model test.

sand. Overall, the deformation modulus of cushion around $100 \mathrm{MPa}$ is reasonable.

5.2. The Influence of the Cushion Thickness on Settlement of the CFG Pile Composite Foundation. This section aims to explore the influence of the cushion thickness on composite

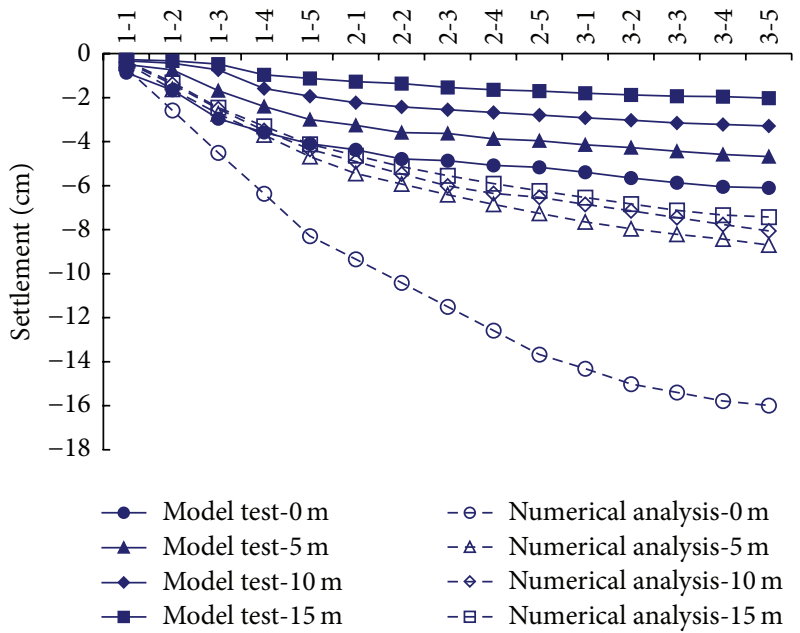

Figure 14: Comparison of interpile soil settlements with time between FEM and model test.

foundation settlement. Deformation modulus of cushion $E_{0}$ $=140 \mathrm{MPa}$ was used in the elastic perfectly plastic model for the analysis while varying the thickness of the cushion $(0,0.5$, $1,1.5$, and $2 \mathrm{~m}$ ). In the FE model, the total thickness of the cushion and subgrade filling remained $6.5 \mathrm{~m}$. Figure 18 shows the FEM results when the thickness of the cushion is 0.5 and $1.5 \mathrm{~m}$, respectively. Distribution of composite foundation settlement under different thickness of cushion with depth is presented in Figure 19. The results (cf. Figure 19) indicate that settlement of the subgrade filling gradually decreases with the increase of the thickness when the thickness of cushion is $0-2 \mathrm{~m}$. When the thickness of cushion is $0-0.5 \mathrm{~m}$, subgrade filling settlement is stable, and the settlement difference is less than $2 \mathrm{~mm}$. While the thickness of cushion is $0.5-1 \mathrm{~m}$, settlement difference reaches $2.1 \mathrm{~cm}$. Keeping increases in the thickness of the cushion, settlement appears to have a relatively consistent increase, which indicates that the thickness of cushion has great influence on subgrade filling settlement in the thickness range of $0.5-1 \mathrm{~m}$. In addition, the cushion settlement increases with the increase of the thickness, and increasing range is less than $0.8 \mathrm{~cm}$. In saturated tailings sand, settlement increases with the increase of the thickness 


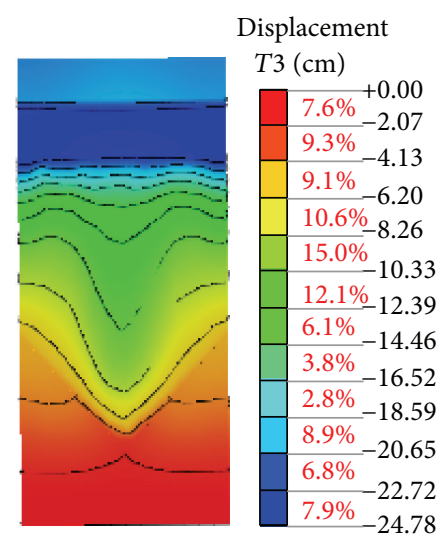

(a) $E_{0}=50 \mathrm{MPa}$

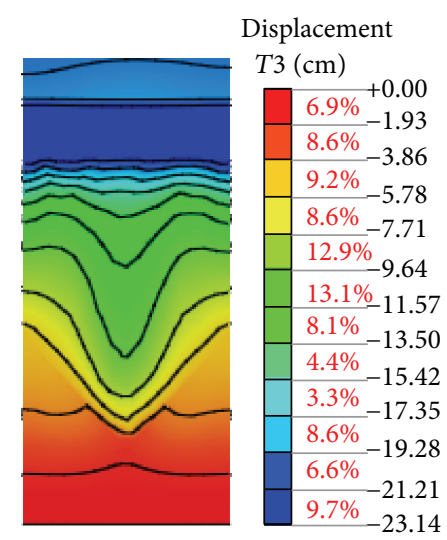

(b) $E_{0}=300 \mathrm{MPa}$

FIGURE 15: Settlement distribution of composite foundation under different deformation modulus.

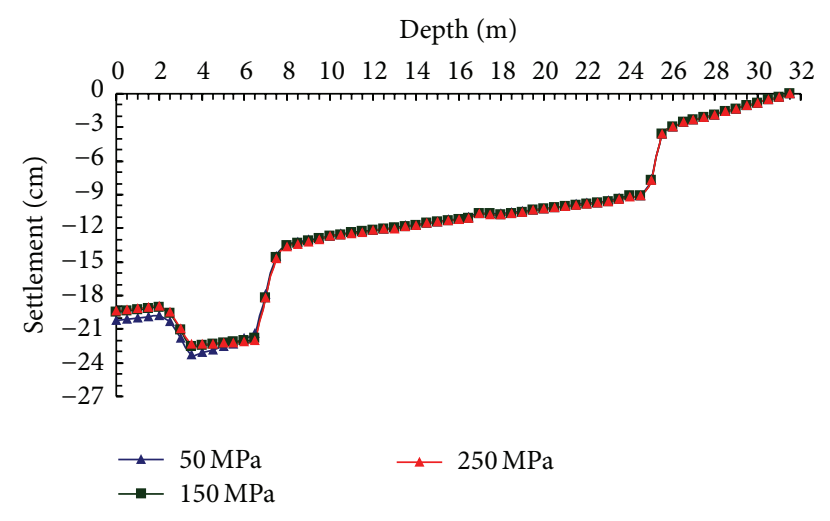

FIGURE 16: Distribution of composite foundation settlement under different deformation modulus with depth.

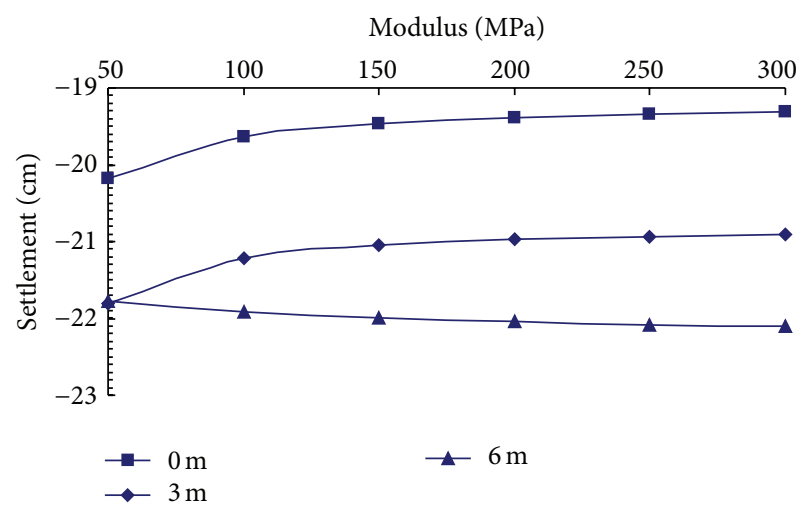

FIGURE 17: Variation of the settlement at central pile position under different modulus.

of cushion. Settlement has great changes and the settlement difference reaches about $1.2 \mathrm{~cm}$ when thickness of the cushion is $0-0.5 \mathrm{~m}$. Meanwhile, when the thickness of cushion is 1.5$2 \mathrm{~m}$, settlement becomes stable. This means that thin cushion will generate great influence on the settlement of saturated tailing sand. Furthermore, when the cushion thickness is less than $1 \mathrm{~m}$, settlement in the various soil layers decreases with depth gradually, and the settlement difference among the soil layers is reduced gradually; the largest settlement occurs in the surface of subgrade filling. When the thickness reaches $1 \mathrm{~m}$, the reduction of settlement in different soil layers tends to be a linear change, which indicates that the settlement is very consistent. When the thickness is more than $1 \mathrm{~m}$, settlement in the soil increases firstly and then decreases with depth; the largest settlement happens to the bottom of the cushion.

In summary, the settlement distribution of composite foundation in different soil layers is very homogeneous when the thickness of cushion is around $1 \mathrm{~m}$, while thick cushion will limit the development of the CFG pile bearing capacity. Therefore, cushion thickness of about $1 \mathrm{~m}$ is reasonable when CFG pile composite foundation is used in the treatment of saturated tailings dam.

\section{Conclusions}

The current paper presented FE model to study settlement behaviors of CFG pile composite foundation. In this model, the variation of the various soil layers settlement was investigated and the results were validated through comparison with the laboratory model test results. In addition, the effects of cushion on the CFG composite foundation settlement were studied. According to the results of settlement studies conducted in this research, some of the main findings are summarized as follows:

(1) According to the FEM results, it is confirmed that the distribution of various soil layers settlement is homogeneous and stable except for the interface of soil layers. After loading, settlement rate of soil between piles (saturated tailings sand) is slower than other soil layers and tends to be stable more rapidly. The increasing range of the settlement in saturated tailings sand is relatively smaller than other soil layers, which is around $2.1 \mathrm{~cm}$.

(2) The variation of settlement of soil between piles in FEM is consistent with laboratory model test with 


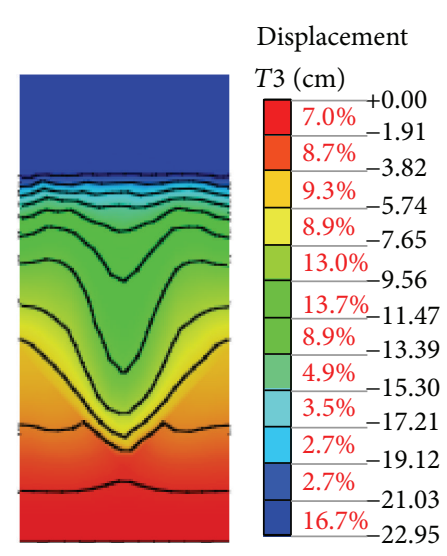

(a) $d=0.5 \mathrm{~m}$

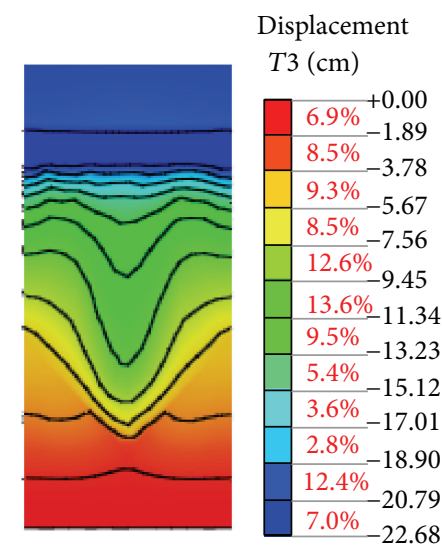

(b) $d=1.5 \mathrm{~m}$

FIGURE 18: Settlement distribution of composite foundation with different thickness of cushion.

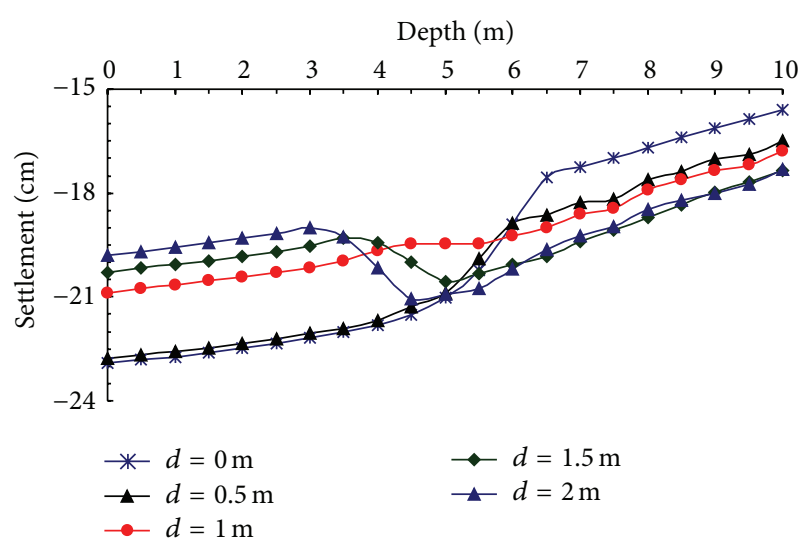

FIGURE 19: Distribution of composite foundation settlement under different thickness of cushion with depth.

depth, load, and time. Furthermore, in both cases, the results demonstrate that the various soil layers settlement of CFG pile composite foundation behavior is consistent and stable, which signifies that saturated tailing dam has obtained a good reinforcement effect after treatment of CFG pile composite foundation.

(3) When the cushion deformation modulus is around 0-100 MPa, increasing the deformation modulus will exert a certain influence on the subgrade filling and cushion. However, there is small effect on the composite foundation settlement when it is more than $100 \mathrm{MPa}$. The thickness of cushion has a relatively large influence on the settlement distribution of the composite foundation. When the thickness of cushion is around $1 \mathrm{~m}$, the settlement has approximately linear decrease with depth. At the same time, the settlement distribution of composite foundation in various layers is more homogeneous than the case of the other cushion thickness. Therefore, it is suggested that modulus of deformation of about $100 \mathrm{MPa}$ and cushion thickness of about $1 \mathrm{~m}$ are reasonable, respectively.
(4) Based on the results of FEM, cushion has the maximum settlement at different loading cases which is $7 \mathrm{~cm}$ larger than that of soil between piles on average. In addition, the settlement control effects are not quite obvious by means of changing the modulus and thickness of the cushion. Therefore, in order to further optimize the design scheme for CFG pile composite foundation and improve the performance characteristics of composite foundation, further experimental studies should be conducted on the new cushion material and the novel connecting type among cushion, pile, and soil of CFG pile composite foundation under flexible foundation.

\section{Conflict of Interests}

The authors declare that there is no conflict of interests regarding the publication of this paper.

\section{Acknowledgments}

This work is financially supported by the Special Fund for Basic Scientific Research of Central Colleges of Chang'an University (Grant no. 31082116011), the Key Industrial Research Project of Shaanxi Provincial Science and Technology Department (Grant no. 2015GY185), and the Integrated Innovation Project of Shaanxi Provincial Science and Technology Department (Grant no. 2015KTZDGY01-05-02).

\section{References}

[1] A.-J. Zhou and B. Li, "Experimental study and finite element analysis of cushion in CFG pile composite foundation," Rock and Soil Mechanics, vol. 31, no. 6, pp. 1803-1808, 2010.

[2] X. Pan, "Study of settlement analysis of composite foundation of CFG piles," Rock and Soil Mechanics, vol. 26, pp. 248-251, 2005.

[3] M. L. Yan, C. L. Wu, and J. Yang, "Study on the composite foundation with cement-flyash-gravel pile," Chinese Journal of Geotechnical Engineering, vol. 18, no. 2, pp. 56-62, 1996. 
[4] F. Song, J. M. Zhang, and G. R. Cao, "Experimental investigation of asymptotic state for anisotropic sand," Acta Geotechnica, vol. 10, no. 5, pp. 571-585, 2015.

[5] X. Weng, Y. Nie, and J. Lu, "Strain monitoring of widening cement concrete pavement subjected to differential settlement of foundation," Journal of Sensors, vol. 2015, Article ID 679549, 7 pages, 2015.

[6] L. Zhao, X. H. Wang, and H. B. Wu, "Settlement calculation of CFG pile composite foundation under flexible foundation," Subgrade Engineering, vol. 3, no. 138, pp. 147-149, 2008.

[7] Y.Zhang and Q. Huang, "Analysis on the properties of semi rigid pile composite foundation," Journal of Geotechnical Engineering, vol. 15, no. 2, pp. 86-93, 1993.

[8] J. W. Duan, X. N. Gong, and G. X. Zeng, "Load transfer behavior of cement treated soil column," Chinese Journal of Geotechnical Engineering, vol. 16, no. 4, pp. 2-7, 1994.

[9] J. Y. Chi, E. X. Song, and Z. Y. Chen, "Proportion of loads carried by the piles and the soil of rigid pile composite-foundation under varying loads," Journal of Tianjin University, vol. 36, no. 3, pp. 359-363, 2003.

[10] M. Zhou, W. C. Yuan, and Y. Zhang, "Seismic material properties of reinforced concrete and steel casing composite concrete in elevated pile-group foundation," Polish Maritime Research, vol. 22, supplement 1, pp. 141-148, 2015.

[11] C. G. Zhang, X. D. Chen, W. Fan, and J. Zhao, "A new unified failure criterion for unsaturated soils," Environmental Earth Sciences, vol. 74, no. 4, pp. 3345-3356, 2015.

[12] J. Lai, J. Qiu, Z. Feng, J. Chen, and H. Fan, "Prediction of soil deformation in tunnelling using artificial neural networks," Computational Intelligence and Neuroscience, vol. 2016, Article ID 6708183, 15 pages, 2016.

[13] J.-B. He, B.-N. Hong, and G.-F. Qiu, "Research on cushion action mechanism of CFG pile composite foundation for expressway," Rock and Soil Mechanics, vol. 25, no. 10, pp. 16641666, 2004.

[14] P. Ji, Y.-Q. Zou, S.-Y. Liu, X.-Y. Zhu, and D.-M. Ma, "Load transfer mechanism of cement-flyash-gravel pile in soft clay by high strain testing," Rock and Soil Mechanics, vol. 26, supplement, pp. 69-72, 2005.

[15] S. G. Huang, "Test study and finite element analysis of CFG composite foundation," Rock and Soil Mechanics, vol. 29, no. 5, pp. 1276-1279, 2008.

[16] H. Zhang, Y. P. Liu, J. H. Li, and Y. Zhou, "In situ test on pile-soil stress ratio of CFG pile composite foundation under embankment load," in Proceedings of the 3rd International Conference on Transportation Engineering (ICTE '11), pp. 15111516, ASCE, Chengdu, China, July 2011.

[17] J. S. Zhang, C. Guo, and S. W. Xiao, "Analysis of effect of CFG pile composite foundation pile spacing on embankment stability based on centrifugal model tests," Applied Mechanics and Materials, vol. 178, no. 181, pp. 1641-1648, 2012.

[18] J.-J. Zheng, S. W. Abusharar, and X.-Z. Wang, "Threedimensional nonlinear finite element modeling of composite foundation formed by CFG-lime piles," Computers and Geotechnics, vol. 35, no. 4, pp. 637-643, 2008.

[19] L. J. Wang, G. L. Ding, S. C. Liu, X. Chen, and Y. Shen, "Study on the determination method for the bearing capacity of CFG pile composite foundation under the flexible foundation in railway," China Railway Science, vol. 29, no. 6, pp. 13-17, 2008.

[20] Y. X. Zhan and G. L. Jiang, "Numerical simulation of the liquefaction resistance characteristics of CFG pile column-net composite foundation," China Railway Science, vol. 29, no. 5, pp. 1-6, 2008.

[21] R. Chen, I. Lee, and L. Y. Zhang, "Biopolymer stabilization of mine tailings for dust control," Journal of Geotechnical and Geoenvironmental Engineering, vol. 141, no. 2, Article ID 04014100, 2015.

[22] R. Chen, L. Y. Zhang, and M. Budhu, "Biopolymer stabilization of mine tailings," Journal of Geotechnical and Geoenvironmental Engineering, vol. 139, no. 10, pp. 1802-1807, 2013.

[23] H. Jiang, "Failure criteria for cohesive-frictional materials based on Mohr-Coulomb failure function," International Journal for Numerical and Analytical Methods in Geomechanics, vol. 39, no. 13, pp. 1471-1482, 2015.

[24] Y. R. Xing, The model test of saturated tailing ore foundation which treated by CFG piles [Ph.D. thesis], Chang'an University, Xi'an, China, 2014.

[25] M.-H. Zhao, L.-P. He, and L. Zhang, "Settlement calculation of CFG pile composite foundation based on load transfer method," Rock and Soil Mechanics, vol. 31, no. 3, pp. 840-844, 2010.

[26] G. L. Ding, S. C. Liu, and L. J. Wang, "Analysis of influence of construction phase on settlement and stress of CFG pile composite foundation," Highway, no. 10, pp. 13-17, 2011.

[27] L. M. Xie, "Numerical analysis on the settlement of CFG composite foundation in Wuhan-Guangzhou special passenger line," Journal of Wuhan University of Technology (Transportation Science \& Engineering), vol. 35, no. 6, pp. 1174-1177, 2011.

[28] J. T. Shahu, M. R. Madhav, and S. Hayashi, "Analysis of soft ground-granular pile-granular mat system," Computers and Geotechnics, vol. 27, no. 1, pp. 45-62, 2000.

[29] H. F. Schweiger and G. N. Pande, "Numerical analysis of stone column supported foundations," Computers and Geotechnics, vol. 2, no. 6, pp. 347-372, 1986.

[30] F.-Y. Liang, L.-Z. Chen, and X.-G. Shi, "Numerical analysis of composite piled raft with cushion subjected to vertical load," Computers and Geotechnics, vol. 30, no. 6, pp. 443-453, 2003. 

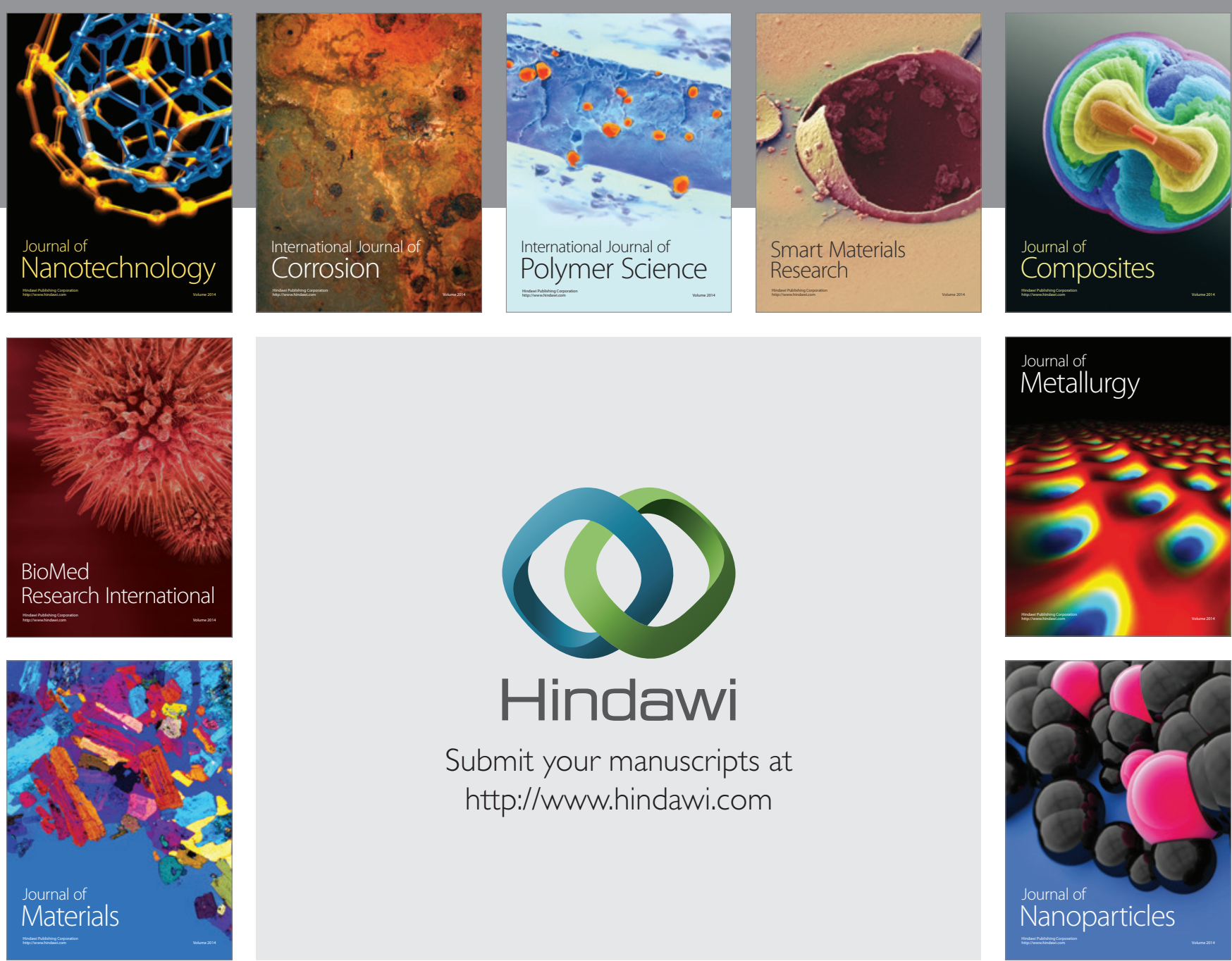

\section{Hindawi}

Submit your manuscripts at

http://www.hindawi.com

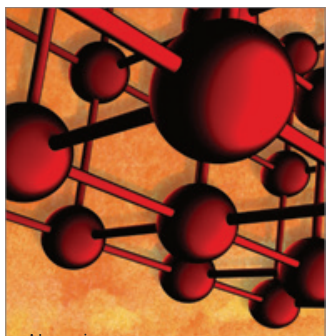

Materials Science and Engineering
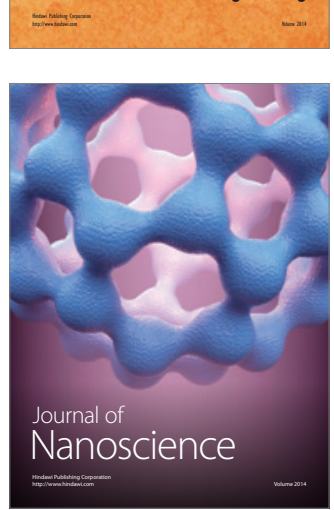
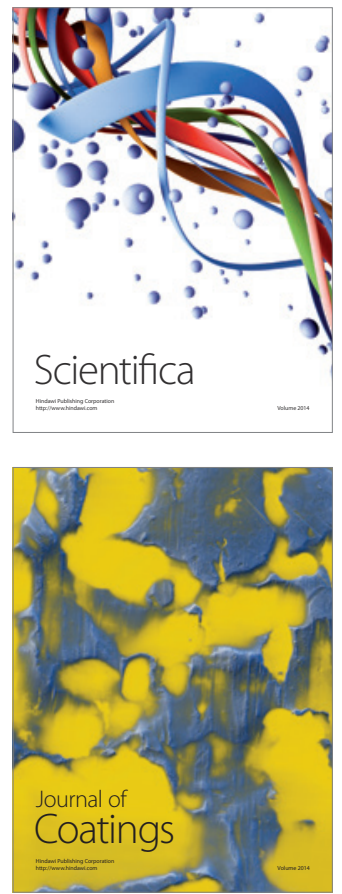
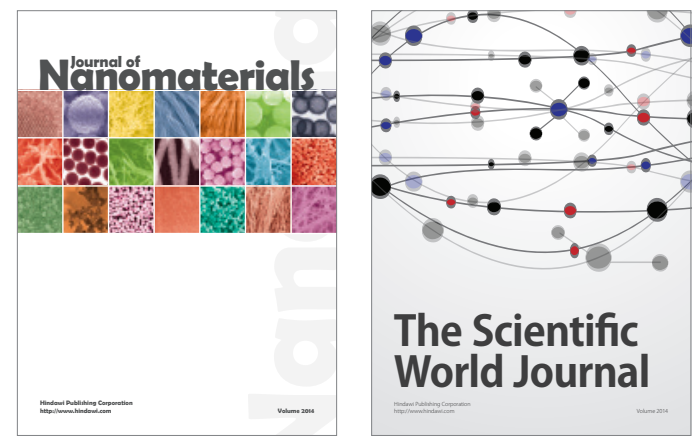

The Scientific World Journal
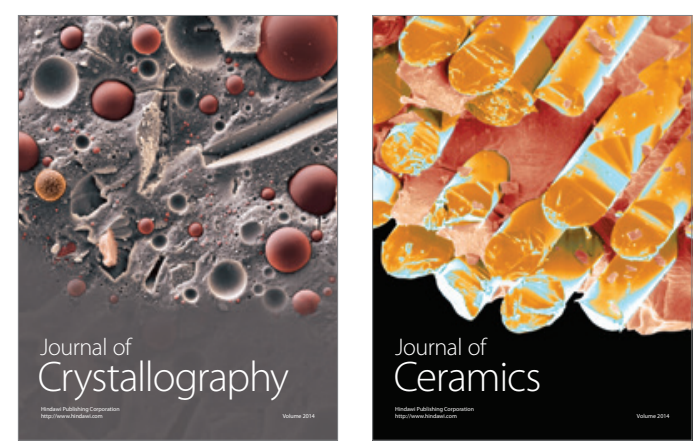
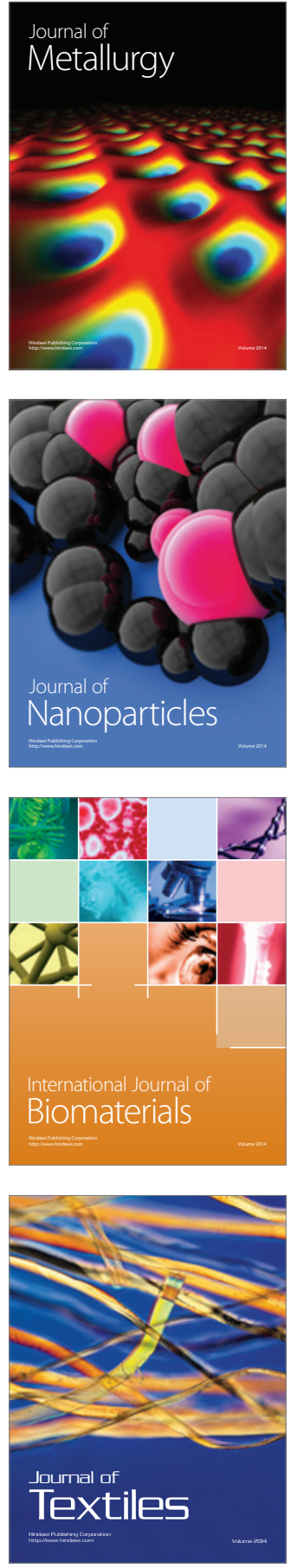